\title{
LAS CARTAS DE LOS “NIÑOS DE RUSIA": DIARIOS DE A BORDO DE UN EXILIO SIN RETORNO'
}

\section{VERÓNICA SIERRA BLAS}

Universidad de Alcalá

RESUMEN Entre 1937 y 1938 el Gobierno de la República española envió a la URSS a 2.895 niños y niñas con el fin de asegurar su supervivencia librándolos de los peligros de la Guerra Civil. Su salida de España formó parte de una importante política de evacuación que dio como resultado el mayor éxodo infantil conocido en la Europa del momento. Muchos de los menores evacuados fueron a parar a países extranjeros. De entre éstos, la URSS fue el que más polémica generó, dado que la mayor parte de los niños y niñas que se refugiaron bajo el régimen de Stalin, al igual que los que fueron a parar a México, nunca pudieron regresar a sus hogares ni volver a reunirse con sus padres, a diferencia de lo que ocurrió con los que tuvieron como destino Francia, Bélgica, el Reino Unido, Suiza o Dinamarca. El objetivo de este trabajo es bucear en las cartas que estos niños y niñas españoles evacuados a la URSS les escribieron a sus padres durante los primeros momentos de su evacuación y que, por suerte, se han conservado en el Centro Documental de la Memoria Histórica de Salamanca; verdaderos "diarios de a bordo" que hoy nos permiten narrar el viaje que hicieron y vivieron estos pequeños refugiados, y entender la manera en que registraron esta experiencia inolvidable con la que iniciaron su particular y dramática historia del exilio del pueblo español.

Palabras clave: Guerra Civil española. Evacuación infantil. URSS. Viaje. Correspondencia.

\section{ABSTRACT THE LETTERS OF THE "CHILDREN OF RUSSIA": ON BOARD DIARIES OF AN EXILE WITHOUT RETURN}

Between 1937 and 1938 the Government of the Spanish Republic sent 2.895 children to the URSS in order to guarantee their survival and free all of them of the dangers of the Civil War. The outing of these children was part of an important politic evacuation that its main result was the greater child exodus known in Europe at that moment. A

1 Este artículo se inserta en el proyecto de investigación "Scripta in itinere". Discursos, formas y apropiaciones de la cultura escrita en espacios públicos desde la primera Edad Moderna hasta nuestros días (Ministerio de Economía y Competitividad del Gobierno de España, HAR2014-51883-P). 
lot of children were evacuated to foreign countries. The Soviet Union, leaded by Stalin, was amongst them, along with Mexico, the most polemical, because almost none of the children could get back home when the war finished, unlike children that were evacuated to France, Belgium, United Kingdom, Switzerland or Denmark. The objective of this article is to study the letters sent by these children evacuated to URSS to their parents during the first period of their evacuation that are conserved in the Documental Center for the Historical Memory of Salamanca; they are trues "on board diaries" that today let us narrate the travel that these little refugees made and lived and to understood the way that they choose to registered this unforgettable experience that began their dramatic and particular history of Spanish people exile.

Keywords: Spanish Civil War. Child Evacuations. URSS. Travel. Letters.

\section{AS CARTAS DE "CRIANÇAS DA RUSSIA": DIÁRIOS DE BORDO DE UM EXÍLIO SEM RETORNO}

Entre 1937 e 1938 o governo da República Espanhola enviou a União Soviética 2.895 crianças, meninos e meninas, com o objetivo de assegurar sua sobrevivência livrando-os dos perigos da guerra civil. Sua saída da Espanha foi parte de uma importante política de evacuação que resultou no maior êxodo infantil conhecido na Europa até aquele momento. Muitos dos menores retirados foram parar em países estrangeiros. Entre esses, a Rússia foi o que gerou maior polêmica, uma vez que a maior parte daqueles meninos e meninas que se refugiaram sob o regime de Stalin, da mesma forma em que aqueles que tiveram o México como paradeiro, nunca puderam regressar aos seus lares nem voltar a reunir-se com seus pais, diferentemente do que ocorreu com os que tiveram como destino a França, a Bélgica, o Reino Unido, a Suiça ou a Dinamarca. O objetivo desse estudo é fazer um mergulho nas cartas que esses meninos e meninas espanhóis, exilados na URSS, escreveram aos seus pais durante os primeiros momentos de sua partida, e que, por sorte, se conservaram no Centro Documental da Memória Histórica de Salamanca; verdadeiros "diários de bordo" que hoje nos permite narrar a viagem que fizeram estes pequenos refugiados, e entender a forma com que registraram esta experiência inesquecivel, que iniciou a particular e dramática história de exílio do povo espanhol.

Palavras-chave: Guerra Civil Espanhola. Exílio infantil. URSS. Viagem. Escrita epistolar. 
No debiera arrancarse a la gente de su tierra o país, no a la fuerza.

La gente queda dolorida, la tierra queda dolorida (GELMAN, 2009, p. XVI).

\section{¡Salvad a la infancia española!}

Que el éxodo infantil derivado de la Guerra Civil española fue uno de los más importantes de todo el siglo XX es a día de hoy una afirmación que nadie puede rebatir. Entre 30.000 y 50.000 niños y niñas españoles, según las fuentes que manejemos, fueron separados de sus familias y evacuados a países extranjeros entre 1936 y 1939; todavía más fueron los que desde el estallido mismo de la contienda y durante la inmediata posguerra se convirtieron, solos o acompañados de sus seres queridos, en perseguidos, refugiados y vagabundos en el interior del país; y podemos contar también por millares los menores que tuvieron que huir de España junto a sus familias y acabaron internados en los campos de concentración franceses una vez que Franco se hizo con la victoria. ${ }^{2}$

Fueron las altas tasas de mortalidad infantil registradas ya en los primeros meses de la contienda, fruto de los continuos bombardeos, del hambre, de la insalubridad y de la falta de medicamentos para poder atender a los niños y niñas enfermos, las que llevaron a las autoridades republicanas a organizar evacuaciones masivas con el fin de salvar a la infancia española de la guerra. En un primer momento, y aprovechando la red de colonias escolares existente, el Gobierno de la República envió a los menores que se encontraban en situaciones de riesgo a zonas alejadas de los frentes de combate dentro del país, sobre todo a Valencia y a Cataluña, ${ }^{3}$ pero a medida que el

2 Para un panorama general sobre los Niños de la Guerra de España véase ALTED, 2005.

3 Acerca de las colonias escolares que acogieron a los niños y niñas evacuados a Valencia y Cataluña en los primeros meses de la contienda véanse CREGO NAVARRO, 1989, p. 299-328; CRUZ, 2006, p. 41-52; y ESCRIVÁ MOSCARDÓ y MAESTRE MARÍN, 2011.
Ejército republicano fue perdiendo posiciones $y$, sobre todo, ante las continuas derrotas sufridas por éste en la llamada Campaña del Norte, librada entre la primavera y el otoño de 1937, decidió recabar la ayuda internacional y mandar varias expediciones de niños y niñas a distintos países que le brindaron su ayuda, convencido de que ésta era la única manera de mantener a los menores con vida y asegurar el futuro del país, una vez que el conflicto terminara (ALONSO CARBALLÉS, 1998).

La propaganda republicana lanzada a través de la radio, la prensa y la cartelística del momento hizo que lemas como "iAyudad a los Niños de España!" o "iSalvad a la infancia española!" calaran hondamente en todo el mundo (Fig. 1). Francia, Bélgica, el Reino Unido, la URSS, México, Suiza y Dinamarca fueron algunos de los países que respondieron positivamente a la llamada desesperada de ayuda de la República española (ALTED, GONZÁLEZ y MILLÁN, 2003). A partir de que se inició la diáspora infantil, la historia de los Niños de la Guerra Civil dejó de ser "propiedad del pueblo español" para pasar a ser parte del "patrimonio internacional" (ZAFRA, CREGO y HEREDIA, 1989, p. 88).

Las evacuaciones infantiles al extranjero, al igual que anteriormente había ocurrido con las del interior, tuvieron dos modalidades principales: por un lado, estaban las de régimen colectivo, en el marco de las cuales los menores convivían en grandes grupos en internados $u$ hogares infantiles supervisados por maestros, médicos y otro personal de apoyo, sostenidos generalmente gracias a subvenciones públicas o privadas; $y$, por otro, estaban las de régimen individual, así denominadas porque los niños y niñas eran acogidos por familias, y por tanto desarrollaban su vida junto a sus padres adoptivos en sus casas particulares, sufragando éstos todos sus gastos y garantizando su asistencia a la escuela (FERNÁNDEZ SORIA, 1987). 
Figura 1 - Cartel de la agrupación anarquista Mujeres Libres instando a la evacuación infantil impreso en Madrid en Gráficas Reunidas durante los primeros meses de la Guerra Civil.

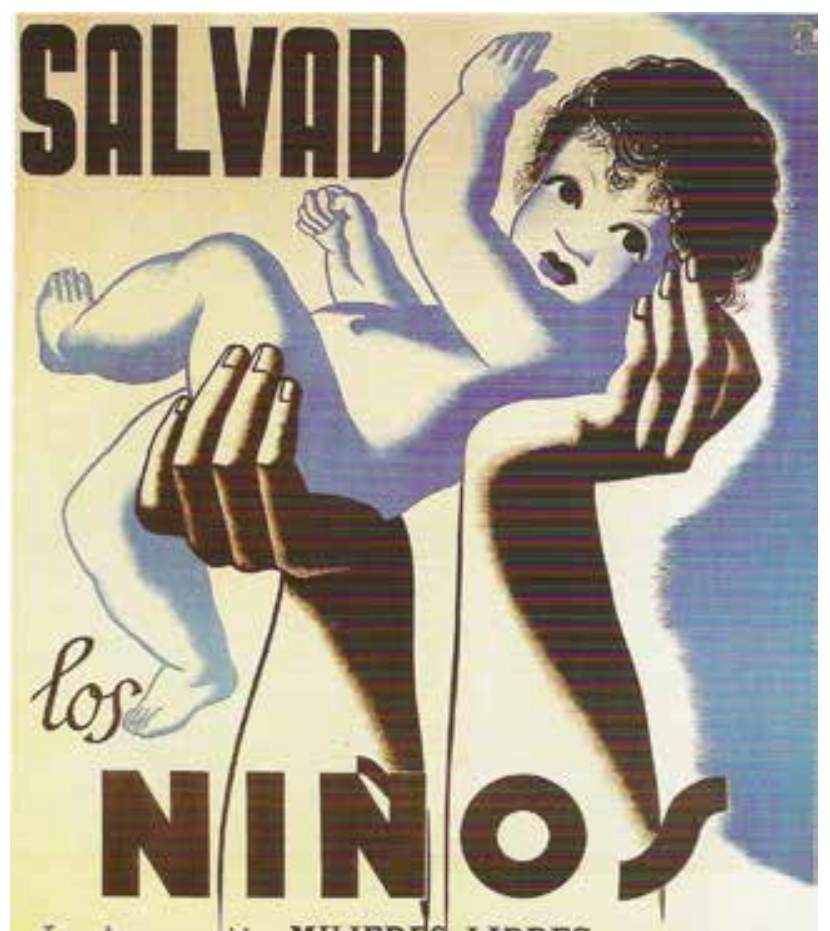

La Agrupación MUJERES LIBRES os aconseja la evacuación de los pequeños, enviándolos al Consejo de Asisteneia Social.

¡MADRES! No disfracéis con nombres sublimes vuestro egoismo.

Fuente: Cfr. "Los niños de la guerra". In: La Guerra Civil española mes a mes. El Mundo, Madrid, Unidad Editorial, no especial, 2005, p. 54.

Independientemente del país de acogida y de las suertes que cada uno de los menores evacuados corrió una vez emprendido su periplo del exilio, todos compartieron el principio de su experiencia de huida y desarraigo: los preparativos para el largo viaje, el embarque y la despedida de las familias en los diferentes puertos de salida de las distintas expediciones, el trayecto recorrido en los barcos, la vida a bordo y la llegada, por fin, al destino. Gracias a algunos de los escritos personales que estos niños y niñas produjeron durante su infancia y luego ya en su vida adulta, dando cuenta o rememorando aquellos primeros momentos de su evacuación, así como a sus testimonios orales, recogidos cuando ya eran adultos o ancianos, en los que el viaje es uno de esos recuerdos imborrables que permanece intacto en su memoria a pesar del paso del tiempo, ha sido posible reconstruir con gran precisión su historia, que es en buena medida también la historia de los derrotados de la Guerra Civil española.

Mi intención en este trabajo es dar a conocer la experiencia vivida en los viajes realizados por una parte de estos niños y niñas españoles a los que la guerra les robó su infancia y les hizo tener que abandonarlo todo: los 2.895 menores que fueron evacuados a la URSS entre marzo de 1937 y octubre de 1938, y a los que la historiografía ha bautizado con el nombre de los "Niños de Rusia". ${ }^{4}$ Para ello, voy a recurrir a las cartas que escribieron a sus familias en distintos momentos de su evacuación para informarles sobre cómo y dónde se encontraban (Fig. 2). ${ }^{5}$ Estas cartas constituyen verdaderos diarios de a bordo que nos permiten entender cómo el viaje fue para todos estos niños y niñas, además de una emocionante aventura y de un episodio tremendamente traumático en sus vidas, la toma de conciencia de la realidad de ser refugiados, de que su país estaba en guerra y de que esa guerra, y quienes la habían provocado (el ejército sublevado y sus aliados), era la culpable de que tuvieran que abandonar su país, separarse forzosamente de sus seres queridos, y empezar una nueva vida.

4 Sobre la Historia de los Niños de Rusia pueden consultarse ZAFRA, CREGO y HEREDIA, 1989; DEVILLARD, PAZOS, CASTILLO y MEDINA, 2001; ALTED, NICOLÁS y GONZÁLEZ, 1999; CASTILLO, 2009; GARRIDO CABALLERO, 2009; COLOMINA LIMONERO, 2010; y MORENO IZQUIERDO, 2017.

5 Para conocer en profundidad la historia de estas cartas véase SIERRA BLAS, 2009a. 
Figura 2 - Carta que Alfonso Ibáñez les envió a sus padres el 24 de junio de 1937 desde Leningrado.

Rusia 23 definio 1937

Lueridosharides salwz os deseo y aber como balage rra nosvrecibiron en Lemingrado ialer como andais decomo andais decomes tote comomosotros andamos. ol prinerdia dellegar mos dirrom soha ides hues nos dieron carne de frollo nosdicron hasteles ienel barco alana dormiamas onel suelo temiamos que ostarunfacola ihara al morrar cafe con han negro comiamos alubias iestatan duras hara lanoche cafe hero enel dro bareo estabamos mefor forquenos daban ratatas istabanbien cocidas inosdaban framblaneo iparcialmorzar nosdaban chocolate Ticafe ihan hararenar arroseco iso-ha deestrella conberra en os llegado abia muchisimagente muchas banderas inosoltanco no ada canconcille camisa is andalias calcetines no anllebadoenautdruses meandado cebillo ifrollos igabon balentin eta combento iale siestacontento carlos end caserio Ulastemandare lassiñas

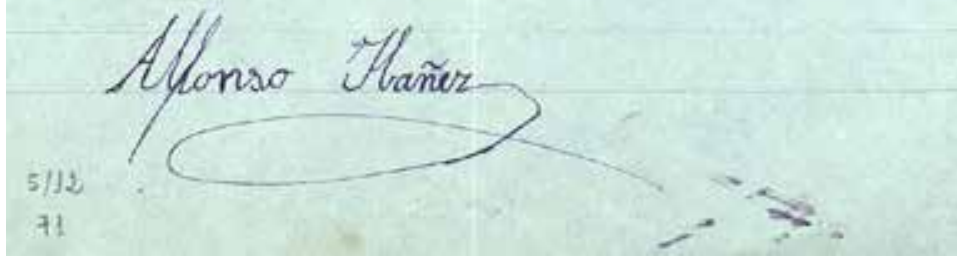

Fuente: Centro Documental de la Memoria Histórica de Salamanca, Pieza Político-Social de Bilbao, caja 5, carpeta 12, no 71.

Fueron un total de cuatro las expediciones infantiles que el Gobierno republicano organizó con destino a la URSS una vez consiguió el beneplácito de Stalin, si bien hubo algunas otras que se desarrollaron de manera extraoficial y que, por lo general, fueron protagonizadas por hijos e hijas de algunos de los dirigentes del Partido Comunista de España (PCE). Estas cuatro expediciones oficiales fueron controladas, como todas las demás que partieron de iniciativas estatales y fueron apoyadas por distintos organismos asistenciales, por el Consejo Nacional de la Infancia Evacuada (CNIE) (ALTED, NICOLÁS y GONZÁLEZ, 1999, p. 34-38), anteriormente Delegación Central de Colonias (DCC), creado en los primeros meses de la guerra y dependiente del Ministerio de Instrucción Pública:

La URSS nos hizo la oferta de [...] recibir a unos cuantos millares de hijos de combatientes para salvarles de los horrores de los bombardeos y para educarles convenientemente. Yo era en- 
tonces ministro de Educación Pública y organicé la salida de varias expediciones de niños de ambos sexos, haciéndoles acompañar de profesores españoles para facilitar la educación en el propio idioma. Estaba convencido de que era una verdadera suerte la de aquellos niños, tanto el alejarles de la guerra como poder ser educados en el país del Socialismo (HERNÁNDEZ, 1953, p. 288).

La primera expedición salió de Valencia el 21 de marzo de 1937 a bordo del buque Cabo de Palos, con alrededor de 90 niños y niñas en su mayoría procedentes de Madrid, Valencia, Alicante, Málaga y Almería, llegando a Yalta (Ucrania) el 28 de marzo. La segunda, compuesta por 1.495 niños y niñas vascos, tuvo lugar en la madrugada del 13 de junio de 1937 a bordo del trasatlántico Habana desde Santurce (Bilbao) (fig. 3), haciendo escala en el puerto de Pauillac (Burdeos) y llegando a Leningrado el 22 de junio a bordo del buque francés Sontay. La tercera partió de Gijón con 1.100 niños y niñas de Santander, Asturias y el País Vasco a bordo del carguero francés Deriguerina el 24 de septiembre de 1937.

Figura 3. Niños y niñas españoles en la cubierta del barco Habana. Bilbao, 1937.

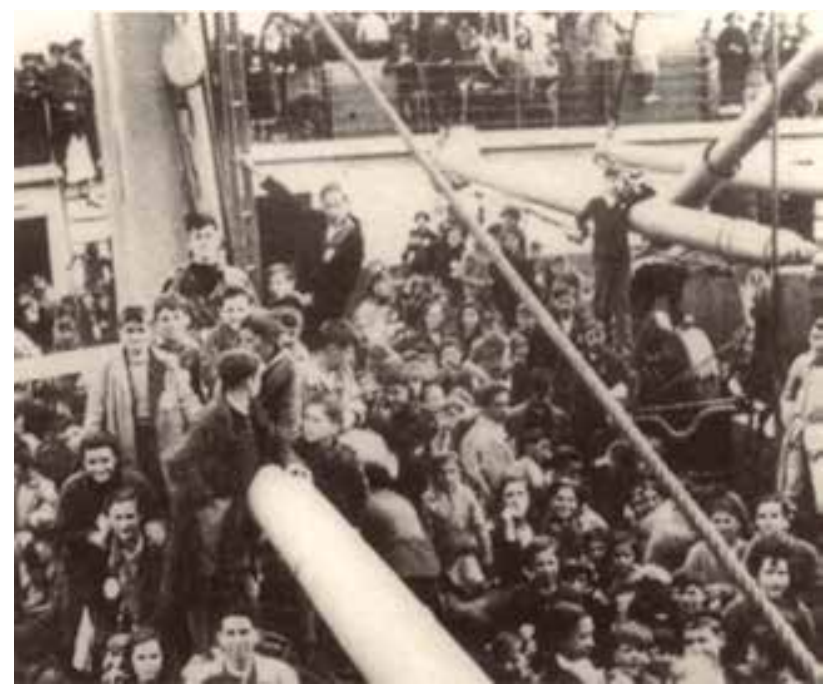

Fuente: Archivo del AMSAB-Instituut voor Sociale Geschiedenis, Gante.

Los menores realizaron dos trasbordos, uno en Francia, en Saint Nazaire (Nantes), al buque soviético Kooperatsia, y otro en el Reino Unido, en Londres, al barco también soviético Feluks Dzerzhinsky, llegando ambos navíos a Leningrado el 4 de octubre. La cuarta y última expedición tuvo como origen Barcelona y como protagonistas a 300 niños y niñas de Murcia, Madrid, Aragón, Cataluña y Valencia, que salieron a finales de octubre de 1938 y que, una vez cruzada la frontera con Francia en autobuses, llegaron en tren hasta el puerto de Le Havre, donde subieron a bordo de dos buques soviéticos, el Marya Uliianova y de nuevo el Feluks Dzerzhinsky, que les condujeron hasta Leningrado. Estos dos barcos no partieron al mismo tiempo y llegaron, por ello, en fechas distintas a la URSS. Mientras que el primero lo hizo a principios de noviembre, el segundo no atracó en el Puerto de Kronstadt hasta principios de diciembre (SIERRA BLAS, 2009a).

\section{"Ahora te voy a contar el viaje que hicimos..."}

Las 225 cartas que he empleado como fuente para reconstruir el viaje realizado por los niños y niñas evacuados a la URSS durante la Guerra Civil española fueron escritas entre el 23 de junio de 1937 (la más antigua) y el 5 de julio de 1938 (la más reciente) por los componentes de la segunda y la tercera expedición de las cuatro anteriormente citadas. La mayoría de sus autores y autoras tenían entre tres y quince años cuando abandonaron España, y procedían de ciudades y pueblos de casi toda la Península, aunque en número fueron muy superiores al resto los originarios del Norte (Asturias, Santander y País Vasco), que vivían fundamentalmente de la industria, de la pesca, de la agricultura y de la ganadería. Sus familias, por lo general, eran familias numerosas y de clase muy humilde; familias trabajadoras que decidieron entregar a algunos de sus hijos e hijas a la República ante el peligro que 
para ellos suponían los continuos ataques aéreos y la imposibilidad de cuidar de ellos debidamente, no sólo por la carestía generalizada que la situación bélica había impuesto en todo el país, sino también por encontrarse sus padres sirviendo al Gobierno legítimo, bien en el frente, combatiendo al enemigo cara a cara tras haber empuñado voluntariamente o no las armas, bien en la retaguardia, cubriendo las necesidades generadas por la guerra (PONS PRADES, 2005).

No son muchos los niños y niñas que hacen referencia a las condiciones espaciales y temporales de la escritura de sus cartas, pero cuando lo hacen todos coinciden en señalar algunos lugares y momentos clave. La mayoría escribió cuando el barco estuvo parado, es decir, cuando realizó alguna escala o cuando llegó a la URSS. Las dos expediciones se detuvieron a los pocos días de zarpar en los puertos franceses de Pauillac (Burdeos) y Saint Nazaire (Nantes), respectivamente; y concretamente la tercera expedición hizo otra escala en Londres, como ya he señalado.

Sabemos que en los puertos franceses e ingleses desembarcó parte del pasaje tanto del Habana como del Deriguerina, ya que junto a los menores que viajaban a la URSS iban también en estos barcos otros grupos de niños y niñas cuyo destino fue Francia o Inglaterra. Aunque no se han conservado las cartas que los menores mandaron a sus familias desde estas escalas aprovechando la vuelta a España de los barcos en los que habían viajado, las que enviaron desde la URSS dan buena cuenta de ellas y de cómo los niños y niñas quisieron informar a sus familias, en cuanto tuvieron la oportunidad de hacerlo, de esa primera parte de su viaje: "Como sabrá salimos de Santurce el 13 del pasado mes. Al anochecer llegamos a Francia, donde escribimos una carta que llevó [a España] el Habana"; "[Te] mandé una carta con una chica y una postal en el Habana"; "Te digo a ver si has recibido la carta que te mandé de Francia". ${ }^{6}$

El lugar de escritura por excelencia fue, pues, el propio barco, tanto los camarotes que los niños y niñas ocuparon, como la cubierta o el comedor, como reflejan las cartas que algunos menores escribieron desde el Sontay, una vez que éste había atracado en Leningrado: "[Te escribo] en la llegada a Rusia en el barco, [pero] no te llegará hasta el jueves de la semana que viene", 7 le explicaba en su carta Marcos Alcón a sus padres.

Figura 4. Grupo de niños y niñas españoles con sus maestros y maestras en un Sanatorio del Mar Negro, sin fecha.

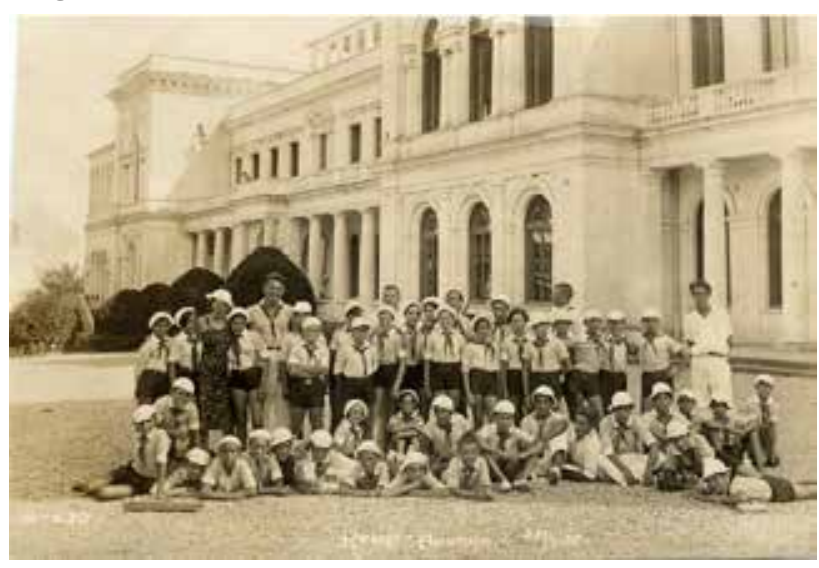

Fuente: Archivo de la Fundación Francisco Largo Caballero, Madrid.

Las misivas fechadas en días posteriores al de la llegada fueron ya escritas desde los balnearios a los que los menores fueron trasladados para reponerse del viaje, en su mayoría ubicados a orillas del Mar Negro, o desde las habitaciones, bibliotecas y salas de estudio de sus "Casas de Niños", grandes y hermosos edi-

6 Carta de un niño/a de nombre desconocido a sus padres y hermanos. [Rusia], 4 de julio de 1937. Centro Documental de la Memoria Histórica de Salamanca (CDMH), Pieza Político-Social de Bilbao (PSB), caja 5, capeta 11, no 55; y carta de Eusebio Inda a sus padres. Sin lugar, sin fecha. CDMH, PSB, caja 5, carpeta 12 , no 73 . Las cartas y fragmentos de cartas citadas en estas páginas han sido transcritas actualizándose su sintaxis y ortografia, con el fin de facilitar su lectura, siguiendo las normas propuestas por SIERRA BLAS, 2009c, p. 14-15.

7 Carta de José Luis y Vicente Alonso a sus padres y hermanos. Sin lugar, sin fecha. CDMH, PSB, caja 5, carpeta 11, no 13. 
ficios que el Gobierno soviético acondicionó en distintos lugares de la Federación Rusa y Ucrania, para que vivieran cómodamente junto a los responsables de las expediciones y que funcionaron hasta el estallido de la II Guerra Mundial (Figs. 4 y 5) (SIERRA BLAS, 2009a, p. 187-189).

Figura 5. Un grupo de niños y niñas españoles en la "Casa de Niños" n.o 9 de Leningrado, 1937.

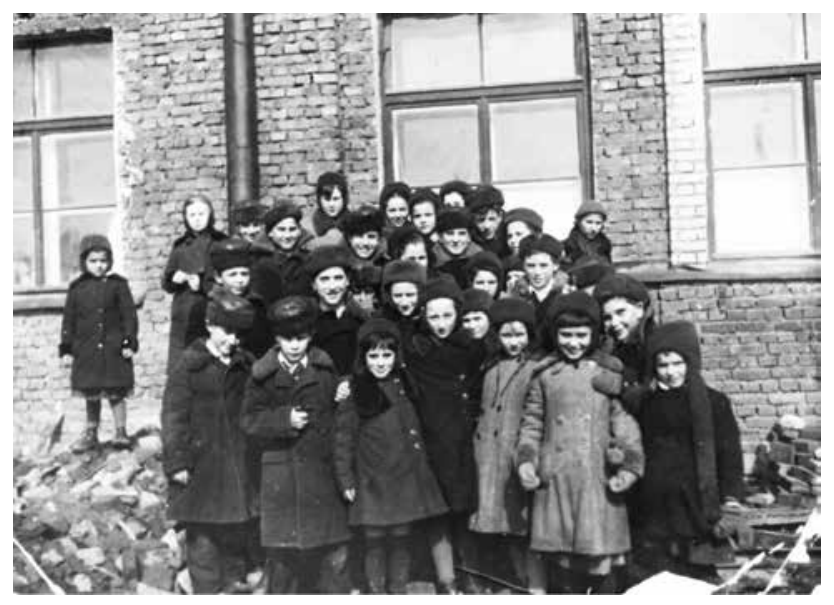

Fuente: Archivo de la Fundación Francisco Largo Caballero, Madrid.

Muchas de estas cartas fueron las primeras enviadas por los niños y niñas a sus casas, pues no todos escribieron desde los barcos, bien porque no quisieron, porque no pudieron o porque sencillamente no se enteraron de que tenían esa posibilidad. Es el caso de la carta que Ángel Alonso le envió a su padre tres días después de su llegada a la URSS, el 25 de junio de 1937:

Te escribo estas cuatro letras para decirte [que] estoy bien [...]. Los pioneros rusos nos han hecho un recibimiento muy bonito [...]. Al desembarcar nos sacaban películas [...]. Hoy nos han dado para almorzar tortilla con dos rebanadas de pan con mantequilla y queso, y luego hemos salido del comedor y nos han dado unas órdenes. Luego nos han dado una caja de bicarbonato y un cepillo para limpiar[nos] los dientes. Luego [he subido] al cuarto, [desde] donde te escribo la carta. ${ }^{8}$

Unas y otras cartas, las escritas desde los

8 Carta de Ángel Alonso a su padre. Leningrado, 25 de junio de 1937. CDMH, PSB, caja 5, carpeta 11, 10-11. barcos o las redactadas desde los balnearios y las "Casas de Niños" una vez que los menores llegaron a su destino, y a pesar de que las separan días o incluso meses, hacen al viaje protagonista indiscutible de la narración. Para los que estaban de camino o acababan de llegar resulta obvio que así fuera, pero para los que llevaban ya un tiempo en la URSS es extraño que el relato del viaje siga ocupando en sus misivas un primer plano. Hay, sin embargo, una explicación para ello. Si los niños y niñas continuaban describiéndoles de manera tan detallada a sus familias el viaje realizado era porque no habían tenido respuesta a sus cartas anteriores, por lo que cada vez que tomaban la pluma, aunque iban incluyendo otras novedades relativas a su vida diaria, como la convivencia con los maestros y compañeros, la escuela donde estudiaban o las actividades culturales y políticas que desarrollaban dentro y fuera de las "Casas", arrancaban su discurso siempre del mismo punto, del punto de partida de su exilio, que no era otro sino el viaje.

\section{La huida}

Muchas cartas se inician relatando el embarque en los puertos de los que partieron las expediciones, el de Santurce (Bilbao) en el caso de la segunda y el de El Musel (Gijón) en el caso de la tercera, entendiéndose este momento como una especie de "rito de paso". Los días previos a la salida fueron vividos por los menores con mucha emoción y gran nerviosismo. Mientras los padres o los responsables de los niños y niñas hacían las maletas y preparaban la documentación que éstos debían llevar consigo, los consejos y recomendaciones se sucedían sin cesar, y el recordatorio de las obligaciones que al estar lejos de sus hogares debían cumplir, se convertía en una serenata sin fin. Las pequeñas maletas de cartón, de cuyas asas colgaba una etiqueta con el nombre y dirección de cada pasajero, así como los es- 
casos enseres que en las mismas cabían y les permitían llevar consigo (apenas unas mudas, algo más de abrigo por si acaso, alguna fotografia familiar y papel para poder escribir cartas a casa) son continuamente nombrados en las memorias y autobiografias que de adultos escribieron algunos de estos menores evacuados, y junto a los infinitos abrazos y besos de padres, madres, hermanos, abuelos, tíos, primos, amigos, etc., recibidos al pie de la pasarela por donde embarcaron, configuran la memoria "fosilizada" de la partida.

Sin embargo, frente a la rica información contenida en las memorias y autobiografias, no hay ni rastro de los preparativos del viaje ni tampoco de las despedidas de las familias en las cartas. Ambos son recuerdos próximos que es mejor mantener borrosos y lejanos para evitar la tristeza que inundó los puertos donde tuvieron lugar los embarques que, por el contrario, sí que aparecen ocasionalmente en esta correspondencia. Unos embarques que duraron horas y horas, que se realizaron generalmente de noche y hasta la madrugada, y siempre que las circunstancias lo permitieron se desarrollaron de manera muy organizada, como les relató el 24 de mayo de 1937 a sus padres y hermanos en su carta Linos Sáez:

Madre, el día que fuimos a embarcar era sábado por la noche. No nos tocó hasta la una de la mañana. Donde se despidió usted de [Carmen] y nosotros dos, Avelina y Linos, nos tuvimos que poner en otra cola y después llamaban por números. Empezaban así del 1 al 100, hasta que llamaron del 1.500 al 1.600 que nos tocó a Avelina, a Linos, a los hijos de [Nebreda] [y] a los hijos de mi padrina. ${ }^{9}$

Tras pasar las primeras horas a bordo de los barcos, la pena por la separación fue poco a poco remitiendo, y el miedo que se apoderó de los niños y niñas cuando se dieron cuenta de

9 Carta de Linos Sáez a sus padres y hermanos. Leningrado, 24 de mayo de 1937. CDMH, PSB, caja 5, carpeta 14 , ํㅡ 11. que estaban solos de verdad y que ya no había vuelta atrás, fue también dejando paso a una nueva sensación que pronto fue contagiando a todos: la de estar viviendo una gran aventura. El barco fue concebido por los menores como un inmenso juguete. El riesgo que el viaje en sí mismo suponía, la incertidumbre de no saber cómo sería lo que les esperaba, el estar fuera de casa para muchos por vez primera, el compartir una experiencia de tal magnitud con otros niños y niñas que se encontraban en su misma situación, etc., convirtió a los menores evacuados en pequeños "robinsones" que, armados de valor, fueron afrontando con la misma valentía que ingenuidad lo que el trayecto les fue trayendo consigo.

En el viaje tuvo lugar una maduración precoz, sobre todo en el caso de aquellos que viajaban al cargo de sus hermanos o primos pequeños, al tiempo que se fue configurando un sentimiento muy fuerte de pertenencia al grupo, que fue en el futuro fundamental no sólo para poder adaptarse a su nueva vida sin olvidar sus raíces, sino también para poder sobrevivir, ayudándose los unos a los otros, cuando llegaron los momentos más duros y difíciles.

\section{La vida a bordo}

Los viajes realizados por estos niños y niñas fueron viajes largos: los de la segunda expedición tardaron nueve días en llegar a su destino, y los de la tercera, diez. Todos estos días en alta mar les hicieron perder la noción del tiempo, y les parecieron una eternidad. No es de extrañar que así fuera si tenemos en cuenta que para muchos era, como acabo de señalar, la primera vez que salían de sus pueblos y ciudades, y la primera vez también que montaban en un barco. En las cartas, los menores hacen referencia de manera recurrente al aburrimiento que para ellos supuso la larga duración del trayecto, que se les hizo aún más largo por la impaciencia con la que esperaban llegar a su 
destino y ver lo que allí les tenían preparado, y sobre todo por verse continuamente rodeados de agua, cielo y nada más: "No se veía nada más que mar y cielo [...]. Estuvimos 8 días sin ver nada [...], y el sábado hizo una niebla y una mar que no se veía nada", apuntaban José y Pilar Fernández en su carta; “Esta es para comunicarles que llegamos sin novedad, [aunque] el viaje fue muy largo y aburrido", afirmaba en la suya Juan Antonio García; “El viaje se nos hizo un poco largo, porque teníamos muchas ganas de ver tierras rusas", les confesaba también a sus padres Francisco Delgado. ${ }^{10}$

Los niños y niñas tuvieron tiempo de sobra, por tanto, para ir registrando en su memoria todo aquello que les llamó la atención, les resultó destacable o les pareció digno de no olvidar, y luego lo pusieron por escrito en sus cartas, donde dieron cuenta de manera muy detallada de su día a día a bordo, tanto de aquellas actividades que formaron parte de su rutina, como pudo ser el horario de comidas, como de aquellas otras que constituyeron en sus vidas una auténtica novedad, como los repartos de juguetes y regalos que la tripulación organizó a bordo para animarles y entretenerles ("[En el barco] estábamos jugando los chicos [a] unos juegos que nos rifaron [...], a mí me tocó uno y me divertía mucho con él”; "[En] el barco me tocó un rompecabezas muy bonito de los tres cerditos") ${ }^{11}$, o los suculentos menús de los que disfrutaron sobremanera, cuyo fin no fue otro que fortalecer su estado físico, dadas las deficiencias alimenticias y, derivadas de ellas, el débil estado de salud que muchos presenta-

10 Carta de Ambrosio y Eugenio [Orbegozo] a sus padres y hermanos. Leningrado, 23 de junio de 1937. CDMH, PSB, caja 5, carpeta 13, no 40; carta de Juan Antonio García a su madre y hermanos. Moscú, 4 de julio de 1937. CDMH, PSB, caja 5, carpeta 12, no 30; y carta de Francisco Delgado a sus padres. [Rusia], 1 de julio de 1937. CDMH, PSB, caja 5, carpeta 11, no 63-64.

11 Carta de Félix Ibáñez a su madre y hermanos. Jarkov, diciembre de 1937. CDMH, Pieza Político-Social de Santander (PSS), serie 0, caja 7, no 32; y carta de Natividad Pérez a sus padres y hermanos. Moscú, 1 de julio de 1937. CDMH, PSB, caja 5, carpeta 13, nos 73-75. ban, de cara a que llegaran sanos, lustrosos y robustos a la URSS.

Sabréis, padres míos, que en el viaje a Francia llegué bien, aunque un poco mareada [...]. Al otro día hicimos traslado a un barco francés, cuyo nombre era Sontay, [donde] nos han dado muy bien de comer: a la mañana, cuando nos levantábamos, nos aseábamos. Tras de esto el desayuno, que consistía en café con leche, pan blanco abundante y chocolate. A eso de las diez, en Bilbao eran las doce, y nos daban la comida, que era un caldo, bien de pasta o de verdura, después o lentejas o patatas con lo mismo. A las tres, que en ésa eran las cinco, nos daban la merienda, siendo ésta galletas con caramelos, y a las seis, que en ésa eran las ocho, nos daban lo mismo o parecido que al mediodía, con postres y salchichón. ${ }^{12}$

Aunque, en general, lo que los menores registraron en su correspondencia fueron las experiencias positivas, sorprendentes o agradables de su viaje, tampoco faltaron las quejas de situaciones que consideraron poco o nada apropiadas, como la libertad con la que podían actuar por falta de control por parte de los adultos que les acompañaban y que dio a éstos más de un susto, o el poco espacio disponible en los barcos hasta que se realizaron los trasbordos, que hizo que algunos menores se quedaran sin camarote y tuvieran que viajar en la cubierta o incluso en las bodegas, como les contó a sus padres en su carta, entre muchos otros, Luis San Pedro: "En el Habana dormíamos en el suelo porque no había camarotes para todos"; ${ }^{13}$ y como confirman también las memorias de Isabel Argentina Álvarez Morán:

Cuando nuestro internado entró en el barco, ya no había sitio, había que dispersar a los niños por distintos lugares y a mí, a mi hermana y a tres niños más nos tocó en la torre del timonel

12 Carta de una niña de nombre desconocido a su padre. Sin lugar, sin fecha. CDMH, PSB, caja 5, carpeta $14, \mathrm{n}$ 은 32.

13 Carta de Luis San Pedro a sus padres. [Rusia], 30 de junio de 1937. CDMH, PSB, caja 5, carpeta 14, no 20. 
[...]. Las bodegas estaban repletas, todo estaba repleto porque hasta en cubierta tuvo que alojarse el último grupo que entró (ÁLVAREZ MORÁN, 2003, p. 186-187).

La falta de espacio dio lugar, por otro lado, a una cierta insalubridad que, unida a ese estado físico algo debilitado de buena parte de los niños y niñas que acabo de señalar, trajo como consecuencia que proliferaran algunas enfermedades, sobre todo las de carácter infeccioso, entre las que la enteritis, la varicela, el sarampión o la pediculosis (piojos), dado su alto grado de contagio, fueron las más sufridas por los pequeños viajeros: "en el barco estuve junto con la Ameli, [...] que se puso mala de sarampión, pero todos los días iba a verla", le informaba a su madre José María García para que supiera que, como le había encomendado que hiciera, cuidaba muy bien de su hermana pequeña; "Emilio está [...] muy mal [...], no saben si es un cólico", avisaba a su padre Francisco Gómez, preocupado porque su primo llevaba varios días "hospitalizado" en la enfermería del barco; "Nos miró el médico y [a] algunas chicas que tenían la cabeza sucia les han cortado el pelo al rape", les contaba aliviada a sus padres y hermanos Servilia Castañeda, pues ella no era una de esas niñas que, como sí que le pasó a su compañera Conchita Magaña, se habían quedado por culpa de los piojos sin sus largas melenas: "[Me han] cortado el pelo a lo mocho [muy corto, como a los chicos] y no sólo a mí, sino a muchas chicas".14

\section{La guerra también viajaba en los barcos}

Aunque a muchos de los niños y niñas sus padres les habían dicho que se marchaban a

14 Carta de José María y Amelia García a su madre. Sin lugar, sin fecha. CDMH, PSB, caja 5, carpeta 12, no 28; carta de Francisco Gómez a sus padres y hermanos. Leningrado, 25 de junio de 1937. CDMH, PSB, caja 5, carpeta 12, no 46; carta de Servilia Castañeda a sus padres y hermanos. Sin lugar, fecha. CDMH, PSB, caja 5, carpeta 11, no 61; y carta de Conchita Magaña a su padre y a su abuela. Odessa, 2 de [julio] de 1937. CDMH, PSB, caja 5, carpeta 13, no 17. una especie de "vacaciones" mientras durase la guerra para evitar que les pasara nada y para que pudieran seguir estudiando (por esas fechas la mayor parte de las escuelas habían ya cerrado sus puertas), ${ }^{15}$ muy pronto todos entendieron que su viaje era una huida en toda regla y que esa huida era, además, necesaria para salvar sus vidas. Lejos de olvidarse de la guerra, la guerra viajó también con ellos en los barcos. Fue una inseparable compañera de viaje.

La amenaza que suponía el enemigo fascista para su supervivencia tomó forma en las persecuciones que algunos de estos barcos que transportaron a los menores evacuados sufrieron por parte de la Marina franquista, como las protagonizadas por el crucero Almirante Cervera, vigilante omnipresente de las costas cantábricas durante toda la contienda. La temida presencia del Cervera se convirtió, de hecho, en uno de los episodios más importantes vividos a bordo, y por ello fue incontablemente relatado en las cartas: "Antes de llegar a Francia vimos a un buque de guerra fascista y también vimos un hidroavión fascista e hicieron el saludo fascista y ponía Virgen del Chamorro [patrona de El Ferrol, La Coruña, donde se construyó el Almirante Cervera en 1925]"; "En el Habana tuvimos un momento de miedo, porque también nos salió a recibir el Cervera y un portaviones alemán"; "Y también le voy a decir lo que nos pasó en el barco, que el Cervera corría detrás de nosotros, pero como venían aviones nuestros no hubo novedad ninguna"; "Antes de llegar a Francia le vimos al traidor barco Cervera, pero como nos iban custodiando cinco barcos franceses y él creyendo que eran barcos españoles rojos, él se marchó ligeramente, que ya no le vimos más".16

15 Sobre la educación en tiempos de la Guerra Civil española remito a MAYORDOMO y FERNÁNDEZ SORIA, 1993.

16 Carta de Gregorio Hernández a sus padres y familiares. [Rusia], 4 de julio de 1937. CDMH, PSB, caja 5, carpeta 12, no 66; carta de José María La Parra a sus 
Los niños y niñas sabían muy bien que la Alemania de Hitler estaba luchando al lado de Franco, y la animadversión hacia todo lo que fuera alemán, pues lo alemán equivalía a destrucción y muerte, se evidencia claramente en otro de los acontecimientos clave del trayecto, que es probable que fuera más metafórico que real: el paso por aguas alemanas. Cuando los barcos atravesaron el territorio marítimo alemán se formó un fuerte oleaje que provocó que muchos menores se mareasen y vomitaran repetidas veces, lo que le llevó a destacar en sus cartas dicha desagradable experiencia, culpando de ella a los enemigos alemanes: al igual que los soldados nazis, que eran "malos", las aguas alemanas también lo eran, y de la misma manera que el ejército de Hitler estaba haciendo daño a España, ellos habían sufrido en sus propias carnes las consecuencias de la "hidra fascista" al atravesar su territorio: "cuando pasamos por aguas alemanas me mareé mucho. Todo el día tenía que estar echada en el suelo. Vomité 7 veces", le contó a su madre Natividad Pérez, al igual que José María Elizalde le narraba a la suya lo malo que se puso al entrar en el Mar Báltico: "Nos mareamos al pasar por Alemania mucho y yo me puse muy malo, como ellos son tan malas, las aguas son tan malas como ellos".17

Las noticias que durante el trayecto les llegaron a los niños y niñas del desarrollo de la guerra fueron muy pocas, pero entre ellas algunas les disgustaron y preocuparon enormemente, como fue el caso de la caída de Bilbao, que tuvo lugar el 19 de junio de 1937, pocos días después de la salida de Santurce de la segun-

padres. [Rusia], 30 de junio de 1937. CDMH, PSB, caja 5, carpeta 13, no 60; carta de José María Álvarez a su padre. Sin lugar, sin fecha. CDMH, PSS, serie O, caja 51, carpeta 7, no 2; y carta de Lucio Rueda a su hermano. Odessa, 12 de febrero de 1938. CDMH, PSS, serie O, caja 51, carpeta 7, $\mathrm{n}^{\text {os }} 83-89$.

17 Carta de Natividad Pérez a sus padres y hermanos. Moscú, 1 de julio de 1937. CDMH, PSB, caja 5, carpeta $13, n^{\text {os }} 73$ a 75; y carta de José María Elizalde a sus padres y hermanos. Sin lugar, sin fecha. CDMH, PSB, caja 5, carpeta 12, n으. 3. da expedición. La radio fue su fuente principal de información en alta mar, como muestra la carta que Ángel Belza les hizo llegar a sus padres y hermanos el 25 de junio de 1937: "Una vez cogieron en el barco [Sontay] una radio que [decía que los] fascistas habían cogido Bilbao y todos estuvimos llorando", y como confirma otra misiva que una de las cuidadoras de este grupo, Ángeles Pérez, le envió a su novio, José Braza, maquinista de El Habana, por las mismas fechas, el 29 de junio: "No te he escrito antes [...] por no saber dónde se encontraba el Habana después de la triste suerte de Bilbao, de lo que nos enteramos [durante el viaje] por Radio Moscú". 18

Aunque la tripulación les hizo creer que se trataba únicamente de un rumor ("Padre, [hay] rumores [de que] Bilbao está rodeado de fascistas") para tranquilizarles hasta que al llegar a destino pudieran explicarles lo ocurrido, los niños y niñas intuyeron que la mala noticia era cierta y se afanaron en recomendar a los suyos que salieran rápidamente de sus casas, además de interesarse por la suerte que habían corrido tras el ataque definitivo del Ejército franquista al País Vasco: "[Madre], usted [márchese de Bilbao] porque [he oído] [...] que [la cosa] está muy mala"; "Bueno, me dices si se ha salvado mucha gente de Bilbao, ya sabemos que lo han tomado los canallas [fascistas] [...]. Me dices si está vivo el padre [...]"19.

Sin duda, la influencia que las opiniones y pareceres de los adultos con los que viajaron tuvieron en las mentes de los menores evacuados fue muy importante, y las cartas, plagadas

18 Carta de Ángel Belza Ventura a sus padres y hermanos. [Rusia], 25 de junio de 1937. CDMH, PSB, caja 5, carpeta 11, no 40; y carta de Ángeles Pérez a su novio, José Braza. Odessa, 29 de junio de 1937. CDMH, PSB, caja 4, carpeta 13, no 71.

19 Carta de José María Elizalde a sus padres y hermanos. Sin lugar, sin fecha. CDMH, PSB, caja 5, carpeta 12, no 3; carta de Santos y Teodora Fuertes a sus padres y hermanos. Sin lugar, sin fecha. CDMH, PSB, caja 5, carpeta 12, no 11; y carta de Amando Gaya a su madre y hermanas, Sin lugar, 8 de septiembre de 1937. CDMH, PSS, serie 0, caja 51, carpeta 7, no 30. 
de consignas de carácter político, especialmente en sus despedidas, dan buena cuenta de ello y reflejan a la perfección el clima ideológico en el que crecieron y vivieron desde que subieron a los barcos y durante todo su exilio: “¡Salud y República!", “¡Viva el Ejército Rojo!”,
“¡No pasarán!”, “iViva la República!”, “iViva la España libre!”, “¡Viva Rusia!” o “¡Viva el camarada Stalin !", son sólo algunas de las fórmulas más repetidas al final de las misivas, escritas por lo general en letras mayúsculas y entre grandes exclamaciones (Fig. 6).

Figura 6 - Carta que José Ortiz de Urbina le envió a su hermano desde Odessa el 5 de diciembre de 1937.

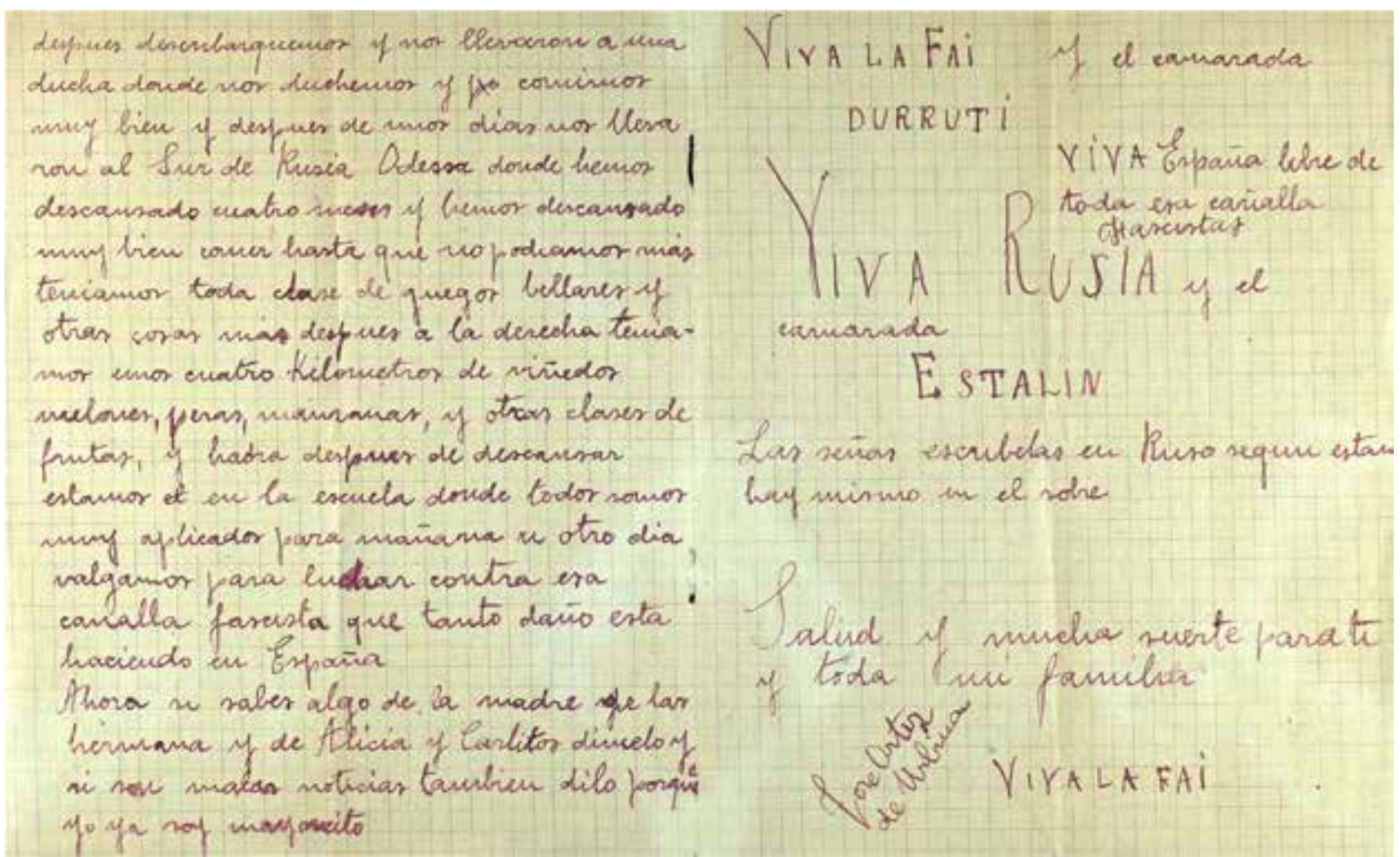

Fuente: Centro Documental de la Memoria Histórica de Salamanca, Pieza Político-Social de Santander, serie O, caja 51, carpeta 7, no 56.

El viaje fue para los niños y niñas un aprendizaje continuo. Todos aquellos a quienes en la escuela o en casa no se les había explicado el porqué de la contienda, supieron de las causas y causantes de la guerra de mano de los responsables de las expediciones, y ello fue clave para que entendieran también las ideas que sus abuelos, sus padres, sus tíos o sus hermanos mayores defendían a muerte en los campos de batalla; ideas que ellos mismos debían igualmente profesar, dado que estaban llamados a cumplir con una importante labor histórica: formarse en el "país del socialismo" para, una vez que la República ganara la guerra, regresar a Españha para construir un nuevo país, a imagen y semejanza de su segunda patria (SIERRA
BLAS, 2009a, p. 221-257). Que supieran quiénes eran los aliados del comunismo y quiénes, por el contrario, eran los aliados del fascismo, las dos fuerzas que cual titanes se enfrentaban en la España y Europa del momento, fue el tema de alguna que otra clase improvisada de Historia y Geografia desarrollada por los maestros que viajaban a bordo, aprovechando el paso de los barcos por distintos territorios. Los menores prestaron mucha atención a esas lecciones espontáneas, y sus cartas dan también buena muestra de ello, ya que muchos fueron capaces de enumerar a sus familias los países que fueron atravesando en su periplo hasta la URSS:

Ahora te voy a [contar] el viaje que hicimos. Cuando salimos de Bilbao, que nos despedi- 
mos de la madre y de todos vosotros, fuimos al barco Habana. Allí estuvimos hasta la mañana. A las cuatro de la mañana le quitaron las cadenas y empezó a andar. Estuvimos un día sin ver tierra y después llegamos a Francia [...], Burdeos. Allí estuvimos dos días en el barco Habana y el último día que estuvimos en el Habana nos dieron un paquete de caramelos, galletas y un panecillo y otras cosas.

Luego nos bajaron a Francia y estuvimos en la estación de Francia. Luego vino el barco Sontay donde embarcamos otra vez. Estuvimos sobre dos horas en el barco y empezó a andar en dirección a la URSS. Por el camino vimos bastantes naciones: Holanda, Bélgica luego un poco más para delante, y estuvimos en las aguas alemanas, que parece que son tan malas como ellos, [pues] había un oleaje muy grande. Luego más para adelante vimos Suecia y otras naciones más. Un poquito más para adelante dos barcos de guerra con grúas y otras cosas más. Luego otro barco igual que el otro, y luego vino a nuestro barco un guardacostas y el capitán montó en nuestro barco y nos sacaban cine desde el guardacostas. Luego muy lejos vimos parte de la URSS y por el camino muchos barcos mercantes.

Cuando nos fuimos acercando a la URSS vimos muchos barcos de guerra rusos y cinco submarinos parados. [Un] poco más tarde, unas dos horas, llegamos a Leningrado y paramos en el puerto. $^{20}$

\section{La llegada a la "tierra prometida"}

La llegada a Leningrado fue para los pequeños evacuados un momento inolvidable. El recibimiento del que fueron objeto por parte del pueblo soviético les llenó de emoción y les hizo sentirse como "como si fuésemos unos héroes que venimos de la guerra y hubiésemos hecho tremendas hazañas", ${ }^{21}$ según le dijo a su padre y a sus hermanos en su carta Emiliano Aza. El Gobierno de Stalin no escatimó en es-

20 Carta de Lucio Rueda a su hermano Victoriano. Odessa, 12 de febrero de 1938. CDMH, PSS, serie O, caja 51, carpeta 7, n $n^{\text {os }} 83-89$.

21 Carta de Emiliano [Aza] a su padre y hermanos. Odessa, 31 de enero de 1938. CDMH, PSS, serie O, caja 51, carpeta 7, 으 6 . fuerzos ni en recursos para hacer de la entrega de los menores a la URSS un importante acto propagandístico, al que revistió de una gran solemnidad:

El día 22 por la mañana apareció ante nuestra vista una de las puntas de Finlandia, que está a la entrada del golfo de su nombre. Dejamos a la izquierda esta parte de tierra y de pronto vimos a la derecha los montes de Ucrania. Seguimos por el golfo hacia delante distrayéndonos con la tierra que a uno y otro lado nuestro se veía. Al mediodía salió a recibirnos un acorazado ruso muy grande $y$, por la tarde, una docena de submarinos nos entretuvieron viéndoles meterse y salir del agua. Unos dos kilómetros antes de llegar a Leningrado se veían numerosas casas en el agua, de modo que parecía una ciudad en el agua.

En el puerto contamos hasta dieciocho submarinos juntos y bastantes barcos de guerra. El barco iba como por una carretera, pues a uno y otro lado de él había unas tiras de tierra con flores muy bonitas, y por esta especie de camino llegamos al fin del viaje, donde nos esperaban numerosas gentes, rusos y rusas, con cantos muy bien cantados que, aunque no los entendíamos, nos agradaba el tono. Enfrente nuestro había situada una casa con gran cantidad de banderas que descendían desde su cumbre hasta el patio, donde estaba el barco. Llegamos a las once de la noche y nos echamos a la cama a la una. Para desembarcar lo antes posible nos levantamos a las seis de la mañana $y$ a las siete empezamos a desembarcar. ${ }^{22}$

La presencia de los medios de comunicación en el muelle, que los niños y niñas no pasaron por alto en sus misivas ("Cuando llegamos [...] nos enfocaron y nos sacaron películas"; “¿No me ha visto retratado en algún periódico?"23) (Fig. 7); las coloridas flores y alegres guirnaldas que engalanaban las dár-

22 Carta de Gilberto Santas a sus tíos y primos. Leningrado, 23 de julio de 1937. CDMH, PSB, caja 5, carpeta 14, no 27.

23 Carta de Víctor Escolar a su padre. Sin lugar, sin fecha. CDMH, PSB, caja 5, carpeta 12, no 7; y carta de Enrique Undiano a su madre y hermana. Moscú, 30 de junio de 1937. CDMH, PSB, caja 5, carpeta 14, no 22. 
senas, así como los edificios y calles aledañas al puerto; y el acompañamiento hasta que los barcos atracaron de esos imponentes submarinos y grandes acorazados que describió tan detalladamente en su carta Gilberto Santas, dejó tan impresionados a los menores que les faltó tiempo para contarles a sus familias tal despliegue de medios realizado en su honor.

Frente al miedo que el Cervera les había hecho pasar en alta mar, los niños y niñas expresaron en sus cartas la admiración que les despertaron, y la sensación de fuerza y seguridad que les transmitieron, esos barcos de guerra soviéticos que salieron tan amistosamente a recibirles, y que muchos pidieron enseguida que fueran enviados a España, junto a la imponente aviación soviética que pronto tuvieron oportunidad de conocer, para ayudar al Ejército republicano a ganar la guerra.

Figura 7 - Grupo de niños y niñas españoles a su llegada al Puerto de Kronstadt (Leningrado) retratados en la cubierta del barco Kooperatsia por la prensa soviética.

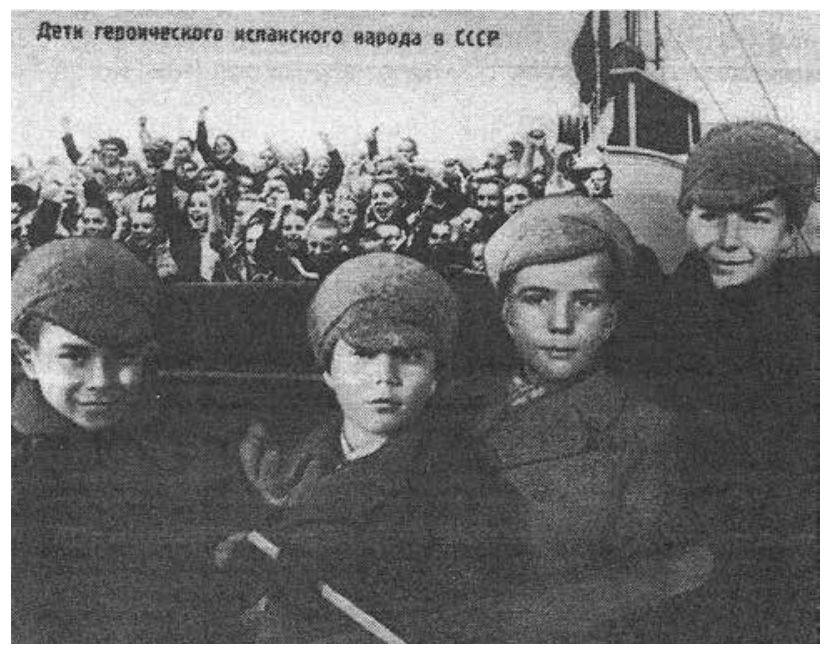

Fuente: Cfr. CIMORRA, Eusebio; MENDIETA, Isidro R.; ZAFRA, Enrique. El sol sale de noche. La presencia española en la Gran Guerra Patria del pueblo soviético contra el nazifascismo. Moscú: Progreso, 1970, p. 71.

Ya parado el barco, los menores salieron a cubierta junto a sus cuidadores y al resto de la tripulación para saludar a la gran multitud que les aplaudía sin cesar y daba vivas a España y a la URSS con sus puños en alto, mientras numerosos grupos de pioneros, perfectamente uniformados con sus trajes de marineros y sus pañuelos rojos atados al cuello, les deleitaban con canciones y bailes tradicionales rusos e interpretaban cada dos por tres La Internacional y el Himno de Riego (el himno de la República española): “Al llegar al puerto había lo menos 300 personas esperando con banderas y nosotros cantando la Internacional y el himno de Riego con el puño en alto". ${ }^{24}$

Ante tal calurosa acogida y la excitación que el ambiente de fiesta supuso para los niños y niñas, además del cansancio acumulado tras el largo viaje, la primera noche en la URSS, que pasaron todavía en el barco, durmieron felices y a pierna suelta, y muy temprano al día siguiente fue cuando comenzaron a desembarcar y a ser conducidos a sus nuevos hogares. Una vez pisaron tierra firme, todos y cada uno de ellos continuaron escribiendo la historia de su evacuación que, a diferencia de lo que ocurrió con los menores españoles enviados a otros países, acabó convirtiéndose para la gran mayoría en un exilio de por vida.

La derrota de la República, primero, y el estallido de la II Guerra Mundial, después, en la que muchos participaron activamente porque entendieron que la misma era la mejor oportunidad para devolver al pueblo soviético lo que había hecho por ellos y recoger el testigo de sus padres y familiares en la lucha contra el fascismo, ${ }^{25}$ hicieron imposible el retorno, que tampoco les fue permitido posteriormente debido a la inexistencia de relaciones diplomáticas entre el régimen franquista y el régimen soviético. Sólo tras la muerte de Stalin, en 1953, las autoridades de ambos países les concedieron la oportunidad de volver a la España que les vio nacer, pa-

24 Carta de un niño/a de nombre desconocido a sus padres y hermanos. Sin lugar, 24 de junio de 1937. CDMH, PSB, caja 5, carpeta 13, no 49.

25 Para una aproximación a la participación de los Niños de Rusia en la II Guerra Mundial pueden verse los trabajos pioneros de VILANOVA, 1969; CIMORRA, MENDIETA y ZAFRA, 1970; PONS PRADES, 1975; y ELPÁTIEVSKY, 2002. 
sados más de 20 años de su huida. Para la mayoría fue ya demasiado tarde. ${ }^{26}$

\section{Luces y sombras de una correspondencia excepcional}

Tal y como he intentado demostrar a lo largo de estas páginas, las cartas que los niños y niñas españoles evacuados a la URSS enviaron a sus familias durante los primeros momentos de un exilio que se preveía temporal y que para casi todos acabó siendo para siempre, constituyen verdaderos diarios de a bordo en los que han quedado registradas las distintas etapas de su viaje, el día a día en el barco y las experiencias y emociones vividas al partir de España, durante el largo trayecto recorrido y al atracar en el país de acogida. Gracias a su conservación resulta posible reconstruir, de mano directa de sus protagonistas, este episodio histórico sin parangón en su tiempo, y conocer la Guerra Civil española desde un punto de vista prácticamente inédito y muchas veces injustamente olvidado en las guerras: el de la infancia que sufrió, tanto o más que los adultos, sus terribles consecuencias.

La narración que los menores realizan del viaje en sus cartas es una narración acompasada con el viaje mismo: el relato tanto del itinerario realizado como de los distintos acontecimientos que tuvieron lugar en alta mar se produce de manera organizada, contándose los hechos de manera cronológica, según fueron realmente ocurriendo. Es un relato que se construye unas veces desde el presente, cuando los niños y niñas aún no han llegado o acaban de llegar a su destino, pero que otras, sin embargo, se escribe de manera retrospectiva, cuando ya han pasado algunas semanas o incluso meses, y todavía no han tenido respuesta de sus familiares, aunque sin variar las formas y tiempos de composición. Las cartas

26 Sobre las repatriaciones a España puede consultarse GARRIDO CABALLERO, 2014, p. 268-276. pueden ser leídas, por ello, como si fueran un diario de viaje, ya que responden a las características principales de este género de escritura, aunque lógicamente se anteponen a éstas, y se mezclan con ellas, las normas y la retórica propias del género epistolar. ${ }^{27}$

Hay algo en las cartas, sin embargo, que rompe con el tono individualista que los diarios de viaje, por lo general, tienen. Si en los diarios de viaje, como también ocurre normalmente en las cartas y en otros géneros autobiográficos, el que habla es el "yo" (AMELANG, 2005), y por ello todos estos documentos constituyen espacios de reflexión y construcción biográfica, en la correspondencia de los Niños de Rusia, aunque sin faltar el "yo", predomina el "nosotros". Han sido muchos los historiadores que han señalado cómo el desarraigo y la pérdida de referentes producidos al abandonar España y dejar atrás a sus familias, por un lado, y el compartir las mismas situaciones y experiencias traumáticas con sus iguales, por otro, unieron de tal manera a los niños y niñas evacuados que la identidad individual se acabó difuminando en una identidad colectiva (MARÍN GÓMEZ, 2003), en la que encontraron su fuerza, su amparo, su apoyo y su refugio. Esa identidad colectiva empezó a fraguarse a bordo de los barcos que les condujeron hasta la URSS, y por ello es posible apreciarla ya en estas primeras cartas en las que los menores relatan su viaje empleando muchas más veces la primera persona del plural, el "nosotros", que la primera del singular, el "yo".

Las cartas que nos cuentan el viaje hasta la URSS realizado por todos estos niños y niñas nos muestran, sin duda, una cara amable del conflicto, por cuanto representan una visión lejana de la España en liza, sólo presente en el recuerdo de las familias que añoraban y en las noticias que sobre la contienda recibían, cual cuentagotas, a través de las radios de los

27 Sobre las relaciones entre el género diarístico y el género epistolar remito a: CROCI y BONFIGLIO, 2002 p. 174200; y CASTILLO GÓMEZ y SIERRA BLAS, 2014, p. 11-21. 
barcos. Son, además, el reflejo de un "milagro" que llena este período oscuro de la historia de algo de luz: la oportunidad de huir de la guerra que las campañas de evacuación organizadas por el Gobierno republicano ofrecieron a la infancia española, consiguiendo salvar la vida de miles y miles de menores.

Sin embargo, son muchas también las sombras que se esconden tras esta correspondencia. La primera de ellas es que la misma no muestra el trauma que la guerra supuso para todos estos niños y niñas, víctimas indefensas de un conflicto en el que no se les permitió permanecer neutrales: "En la España partida en dos los niños tuvieron que ser beligerantes porque los bombardeos, el éxodo permanente, la ausencia del padre soldado, preso, fusilado; el hambre, el frío, el pánico, todo en su conjunto o por separado se ensañó con ellos" (PAMIÈS, 1977, p. 9).

No fueron, sin embargo, los hechos inherentes a la propia guerra, como los bombardeos o las operaciones militares, los que más daño les hicieron. De las secuelas físicas y psíquicas que éstos trajeron consigo pudieron recuperarse, unos mejor que otros, tarde o temprano. Lo que realmente les causó un daño irreversible fue la separación de sus familias (YOUNES, 1999). La pérdida de su mundo afectivo de manera tan temprana les hizo vivir durante toda su vida desamparados, descolocados, fuera de lugar, sintiéndose incomprendidos, creyéndose huérfanos sin muchos de ellos serlo, expatriados de sus raíces, con miedo ante un futuro siempre incierto, soñando con un retorno que nunca llegaba y que acabó siendo para muchos una forma de existencia frustrada y para otros tantos una especie de "muerte lenta", como definió al exilio Adolfo Sánchez: “[El exilio es] una muerte lenta que recuerda su presencia cada vez que se arranca la hoja del calendario en el que está inscrito el sueño de la vuelta [...]" (SÁNCHEZ, 1997, p. 38).

La segunda de estas sombras que esconde la correspondencia de los Niños de Rusia es que apenas hay en ella rastro del exhaustivo control y de la férrea censura al que el intercambio epistolar entre los menores y sus seres queridos estuvo constantemente sometido. Los responsables de las expediciones, al igual que hicieron luego en las "Casas de Niños", supervisaron la escritura de las cartas. Nada en ellas debía ser negativo, preocupante o criticable: los niños y niñas debían dar cuenta del desarrollo modélico de las evacuaciones, del inmejorable trato recibido por parte de sus cuidadores y de la tripulación a bordo y de las excelentes condiciones en las que habían realizado su viaje hasta llegar al país de acogida, disfrutando de innumerables privilegios, como la abundante comida o los juguetes que se les regalaron, que les colmaron de felicidad y alegría. La espontaneidad infantil se plegó, pues, a las exigencias ideológicas y propagandísticas, y fueron muchas las maneras en las que intervinieron los adultos en la escritura de sus cartas para velar por esta "buena imagen" de las evacuaciones infantiles, desde escribir en nombre de los más pequeños (delegación gráfica), pasando por sugerir temas a los que ya se manejaban con la pluma, hasta directamente corregir o tachar aquellas afirmaciones que podrian suponer un problema y empañar la loable labor humanitaria de la República española (SIERRA BLAS, 2009b, p. 228-233).

Por otro lado, y aunque la correspondencia de la infancia evacuada solía circular por valija diplomática y tenía otorgada una franquicia postal que hacía que las cartas pudieran ser enviadas gratuitamente (sin sello) (DUROUX y THIERCELIN, 1996), al igual que todas las misivas procedentes o dirigidas al extranjero, las cartas de los Niños de Rusia debían pasar obligatoriamente por la censura postal, establecida por Orden de 15 de agosto de 1936 del Ministerio de Comunicaciones y del Servicio Internacional de Correos (Figs. 8 y 9) (HELLER, 1995, p. 35). 
Figura 8 - Sobre que contenía la carta que José Garrido le envió a su madre desde Moscú el 9 de enero de 1938 con la marca de la censura postal española.

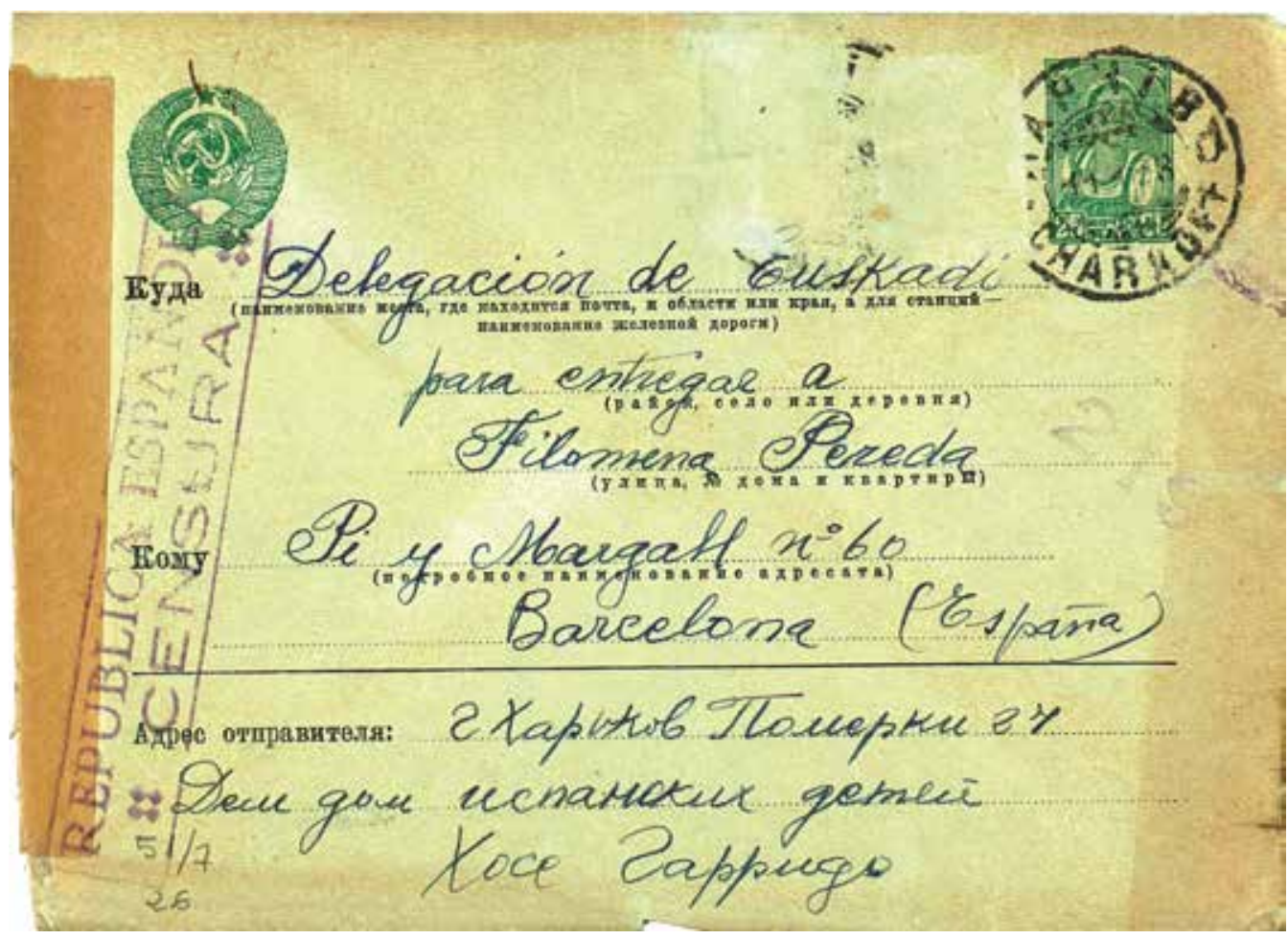

Fuente: Centro Documental de la Memoria Histórica de Salamanca, Pieza Político-Social de Santander, serie 0, caja 51, carpeta 7, no 26.

Figura 9 - Marca de censura republicana catalogada como "RB3.12a”.

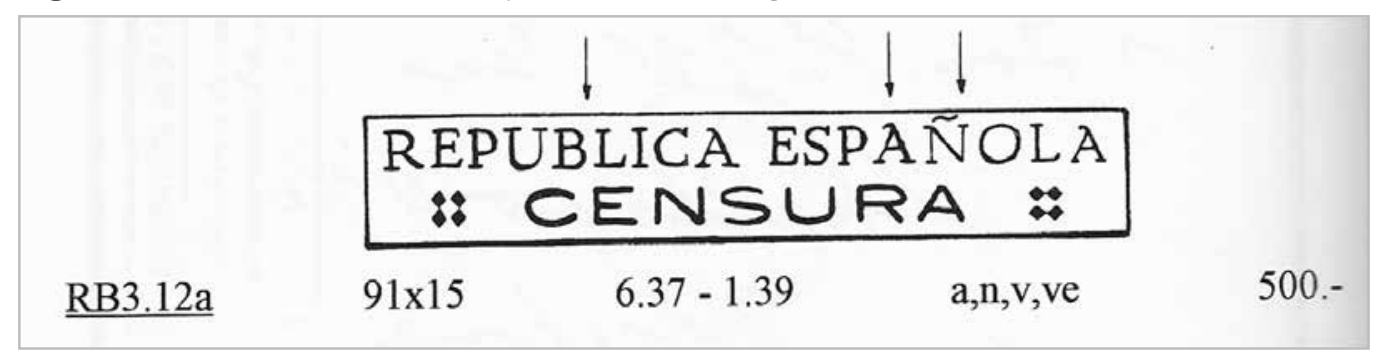

Fuente: Cfr. HELLER, Ernst L. Marcas utilizadas por la censura republicana durante la Guerra Civil española. Madrid: Lindner Filatélica Ibérica, 1995, p. 76.

El exhaustivo examen de las cartas que debían realizar los censores ralentizaba enormemente la entrega de la correspondencia, y el aumento exponencial del flujo postal propio de un tiempo de guerra, en el que todo el mundo tiene necesidad de escribir para saber de los suyos, colapsaba continuamente las oficinas de correos, lo cual explica el desajuste existente, en algunos casos, entre las cartas de los menores y las respuestas de las familias, o en otros, la no llegada a destino de las cartas y el consecuente silencio postal.

Pero aparte de estas dos sombras señaladas, en la historia de las cartas de los Niños de Rusia hay una tercera sombra, mucho más negra e imprevisible, que debo desvelar antes de dar por terminado este artículo. Desde el mismo momento en que los padres o tutores inscribieron a sus hijos e hijas en las expediciones 
a la URSS, los responsables de las evacuaciones quisieron asegurarse de que pudieran entablar correspondencia con ellos durante el tiempo que fueran a estar separados, motivo por el cual en la ficha que debían entregar con los datos de los menores antes de que éstos embarcaran debía constar una dirección postal de contacto "segura" (Fig. 10) (SIERRA BLAS, 2009a, p. 125).

Figura 10 - Ficha de evacuación de María Pilar Fernández López emitida por el Departamento de Asistencia Social de Euzkadi (País Vasco).

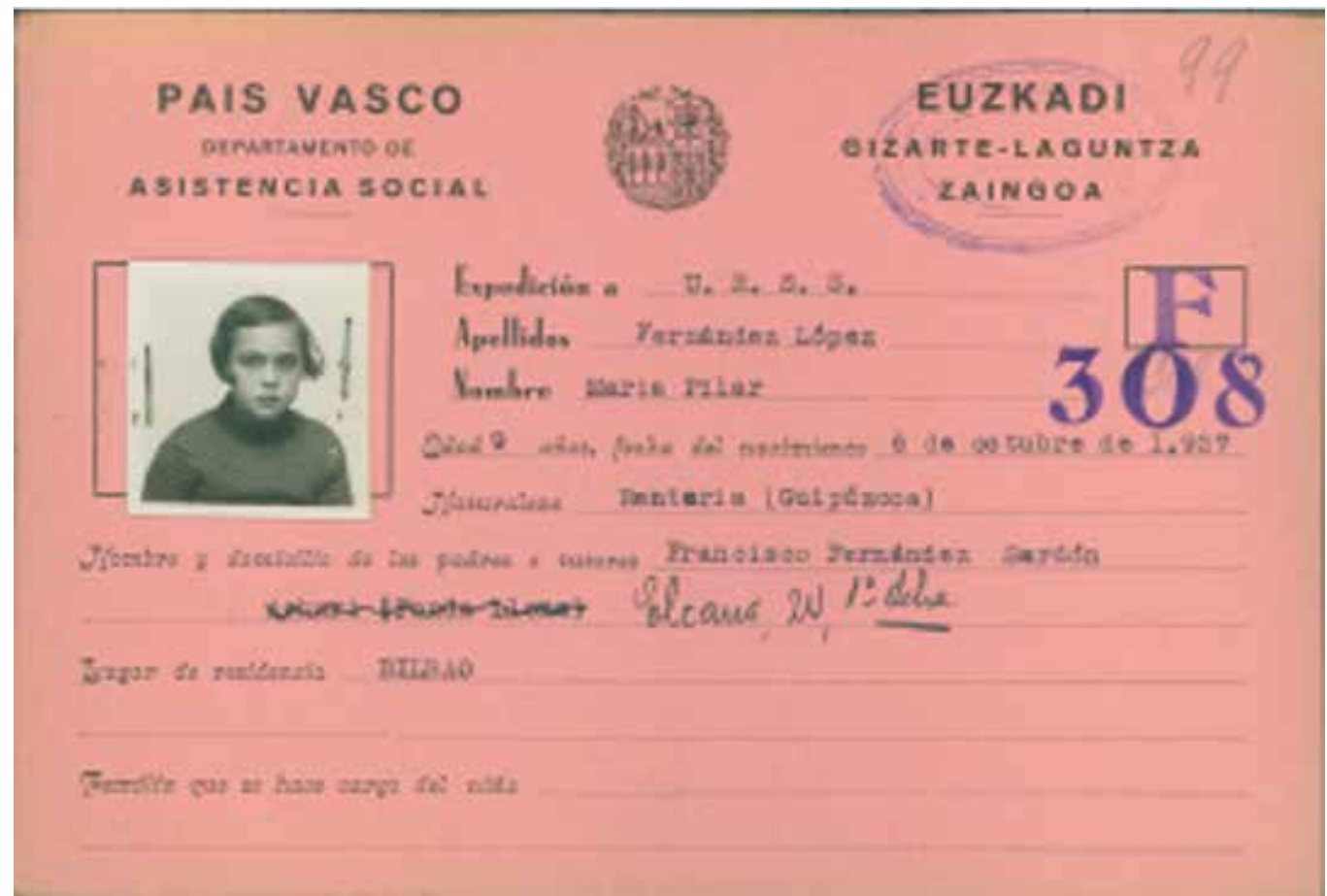

Fuente: Centro Documental de la Memoria Histórica de Salamanca, Pieza Político-Social de Santander, serie 0, carpeta 95, expediente 2, fol. 99.

Nadie contaba entonces con la posibilidad de que la República perdiera la Campaña del Norte y ni mucho menos con que pudiera perder la guerra. Los familiares de los niños y niñas evacuados se convirtieron casi al mismo tiempo que éstos en refugiados, si no en perseguidos o, lo que es aún peor, en desaparecidos. Aunque los menores les enviaron cartas de forma frecuente, como les habían prometido hacer, para darles cuenta de su estado y relatarles todo lo que hacían (la correspondencia permitía a los progenitores seguir manteniendo la potestad sobre sus vástagos en la distancia) (SIERRA BLAS, 2017), además de para interesarse por ellos, estas cartas casi nunca les llegaron. Y el motivo principal no fue la mala gestión administrativa de los servicios de censura postal, sino el no poder encontrar a los destinatarios. Al haber tenido que abandonar sus hogares, los familiares de los niños y niñas no pudieron recibir sus cartas, que acabaron siendo devueltas y "archivadas" en las Delegaciones de Asistencia Social republicanas a la espera de que los responsables de las mismas pudieran dar con su paradero, cosa que ocurrió sólo en contadísimas ocasiones.

Cientos de cartas no entregadas se fueron así acumulando en las oficinas de estas Delegaciones durante la contienda sin que pudieran darse curso hasta que la guerra fue llegando a su fin y fueron incautadas por las tropas franquistas. Cada vez que el Ejército de Franco conquistaba un territorio, su Servicio de Recuperación de Documentos (SRD) arramplaba con todos los papeles que encontraba a su paso y que podian ser de utilidad para buscar, cuando 
llegara el momento, a los que habían luchado al lado de la República y debían, por ello, ser castigados (MICHONNEAU, 2005). Así, lejos de cumplir con su cometido original, que era sencillamente dar cuenta a los padres y familiares de que se encontraban en perfecto estado de salud tras haber realizado su viaje hasta la URSS y saber de ellos, las cartas de los Niños de Rusia acabaron sirviendo al aparato represivo franquista como pruebas para condenar a sus destinatarios, engrosando algunos de los miles de expedientes que llegaron al Tribunal para la Represión de la Masonería y el Comunismo, hoy conservados en el Centro Documental de la Memoria Histórica de Salamanca (SIERRA BLAS, 2009b, p. 242-244).

\section{Referencias}

ALONSO CARBALLÉS, JesúS J. 1937. Los niños vascos evacuados a Francia y a Bélgica. Historia y memoria de un éxodo infantil, 1936-1940. Bilbao: Asociación de Niños Evacuados el 37, 1998.

ALTED, Alicia. La voz de los vencidos. El exilio republicano de 1939. Madrid: Aguilar, 2005.

ALTED, Alicia; GONZÁLEZ, Roger; MILLÁN, María José. (Eds.). El exilio de los niños. Catálogo de la exposición. Madrid: Fundación Pablo Iglesias; Fundación Francisco Largo Caballero, 2003.

ALTED, Alicia; NICOLÁS, Encarna; GONZÁLEZ, Roger. Los niños de la guerra de España en la Unión Soviética. De la evacuación al retorno (1937-1999). Madrid: Fundación Francisco Largo Caballero, 1999.

ÁLVAREZ MORÁN, Isabel Argentina. Memorias de una niña de la guerra. Gijón: Ayuntamiento de Gijón; Fundación Municipal de Cultura, Educación y Universidad Popular, 2003.

AMELANG, James. (Coord.). De la autobiografía a los ego-documentos: un fórum abierto. Cultura Escrita \& Sociedad, Gijón, n. 1, p. 15-195, sep. 2005.

CASTILLO, Susana. Mis años en la escuela soviética. El discurso autobiográfico de los niños españoles
Lamentablemente, y durante mucho tiempo, como muestran las marcas de los represores, quienes subrayaron todos los nombres, lugares y datos importantes que en las cartas encontraron, las palabras de los Niños de Rusia fueron la prueba del "delito de rebelión" de sus seres queridos; pero una vez muerto el dictador y comenzada en España la transición a la democracia, sus cartas sirvieron para demostrar las atrocidades perpetradas por el régimen franquista y para dar a conocer la injusticia que vivieron todos estos niños y niñas, y sus familias, pudiendo a partir de entonces escribir gracias a ellas una historia "al revés" que ha dado la oportunidad de devolver la voz a los vencidos tras largos años de olvido y de silencio.

en la URSS. Madrid: Los libros de la Catarata, 2009.

CASTILLO GÓMEZ, Antonio; SIERRA BLAS, Verónica. "¿Por qué ustedes son capaces de imaginarse un mundo sin cartas?". In: CASTILLO GÓMEZ, Antonio; SIERRA BLAS, Verónica. (Dirs.). Cinco siglos de cartas. Historia y prácticas epistolares en las Épocas Moderna y Contemporánea. Huelva: Servicio de Publicaciones de la Universidad de Huelva, 2014. p. 11-21.

CIMORRA, Eusebio; MENDIETA, Isidro R.; ZAFRA, Enrique. El sol sale de noche. La presencia española en la Gran Guerra Patria del pueblo soviético contra el nazi-fascismo. Moscú: Progreso, 1970.

COLOMINA LIMONERO, Immaculada. Dos patrias, tres mil destinos: vida y exilio de los niños de la Guerra de España evacuados a la Unión Soviética. Madrid: Cinca; Fundación Francisco Largo Caballero, 2010.

CREGO NAVARRO, Rosalía. Las colonias escolares durante la Guerra Civil (1936-1939). Espacio, Tiempo y Forma, Madrid, serie V, n. 2, p. 299-328, 1989.

CROCI, Federico; BONFIGLIO, Giovanni. El baúl de la memoria: testimonios escritos de los inmigrantes en el Perú. Lima: Fondo Editorial del Congreso de la 
República del Perú, 2002.

Cruz, José Ignacio. Colonias escolares y Guerra Civil. Un ejemplo de evacuación infantil. In: A pesar de todo dibujan. La Guerra Civil vista por los niños. Catálogo de la Exposición (Madrid, 20 de noviembre de 2006 al 18 de enero de 2007). Madrid: Biblioteca Nacional de España; Fundación Winterthur, 2006. p. 41-52.

DEVILLARD, Marie Jose; PAZOS, Álvaro; CASTILLO, Susana; MEDINA, Nuria. Los niños españoles en la URSS (1937-1997): narración y memoria. Barcelona: Ariel, 2001.

DUROUX, Rose; THIERCELIN, Raquel. Los niños del exilio: asignatura pendiente. In: CUESTA, Josefina; Bermejo, Benito. (Coords.). Emigración y exilio. Españoles en Francia, 1936-1946. Madrid: Eudema, 1996. p. 167-182.

Elpatievsky, Andrey. Ispanskaia emigratzia v Sovetskom Soyuze. Istoriografia i istochniki, popytka interpretatsii. Tver: Izdatelstvo Guers, 2002. [Traducido al español. ENCINAS MORAL, Ángel Luis. Emigración española en la URSS. La historiografía y las fuentes, un intento de interpretación. Madrid: Exterior XXI, 2008].

ESCRIVÁ MOSCARDÓ, Cristina; MAESTRE MARÍN, Rafael. De las negras bombas a las doradas naranjas. Colonias escolares, 1936-1939. Valencia: L'Eixam Éditions, 2011.

FERNÁNDEZ SORIA, Juan Manuel. La asistencia a la infancia en la Guerra Civil. Las colonias escolares. Historia de la Educación, Revista interuniversitaria, Salamanca, n. 6, p. 83-126, 1987.

GARRIDO CABALLERO, Magdalena. Compañeros de viaje. Historia y memoria de las asociaciones de amistad hispano-soviéticas. Murcia: Universidad de Murcia, 2009.

GARRIDO CABALLERO, Magdalena. El exilio republicano rumbo a la Unión Soviética. Repatriaciones, retornos y situación actual de los "Niños de la Guerra". In: AZNAR SOLER, Manuel; LÓPEZ GARCÍA, José Ramón; MONTIEL RAYO, Francisca; RODRÍGUEZ, Juan. (Coords.). El exilio republicano de 1939: viajes y retornos. Sevilla: Renacimiento, 2014. p. 268-276.
GELMAN, Juan. Bajo la lluvia ajena. Barcelona: Libros del Zorro Rojo, 2009.

HELLER, Ernst L. Marcas utilizadas por la censura republicana durante la Guerra Civil española. Madrid: Lindner Filatélica Ibérica, 1995.

HERNÁNDEZ, Jesús. Yo fui un ministro de Stalin. México D. F.: Editorial América, 1953 [1]a edición, Madrid: G. del Toro, 1974].

MARÍN GÓMEZ, Isabel. Identidad y representación. La construcción de una memoria común. La infancia desterrada. In: ALTED, Alicia; GONZÁLEZ, Roger; MILLÁN, María José. (Eds.). El exilio de los niños. Catálogo de la exposición. Madrid: Fundación Pablo Iglesias; Fundación Francisco Largo Caballero, 2003. p. 211-223.

MAYORDOMO, Alejandro; FERNÁNDEZ SORIA, Juan Manuel. Vencer y convencer. Educación y política. España, 1936-1945. Valencia: Universitat de València, 1993.

MICHONNEAU, Stéphane. Les papiers de la guerre, la guerre des papiers. L'affaire des archives de Salamaque. Sociétés et Représentations, París, n. 19, p. 250-267, 2005.

MORENO IZQUIERDO, Rafael. Los Niños de Rusia. Madrid: Crítica, 2017.

PAMIÈS, Teresa. Los niños de la guerra. Barcelona: Bruguera, 1977.

PONS PRADES, Eduardo. Republicanos españoles en la Segunda Guerra Mundial. Barcelona: Planeta, 1975.

PONS PRADES, Eduardo. Los niños republicanos. El exilio. Madrid: Oberón, 2005.

SÁNCHEZ, Adolfo. Recuerdos y reflexiones del exilio. Barcelona: Grupo de Estudios del Exilio Literario (GEXEL) de la Universitat Autònoma de Barcelona, 1997.

SIERRA BLAS, Verónica. Palabras huérfanas. Los niños y la Guerra Civil. Madrid: Taurus, 2009a.

SIERRA BLAS, Verónica. España que perdimos, no nos pierdas. Una lectura entre líneas de la correspondencia privada de los Niños de Rusia. In: NÚÑEZ 
SEIXAS, Xosé Manoel; GONZÁLEZ LOPO, Domingo. (Coords.). Amarras de tinta. Emigración transoceánica e escrita popular na Península lbérica, séculos XIX-XX. Santiago de Compostela: Universidade de Santiago de Compostela; Consello da Cultura Galega, 2009b. p. 215-245.

SIERRA BLAS, Verónica. Criterios de transcripción. In: SIERRA BLAS, Verónica (Dir.); MARTíNEZ MARTíN, Laura; MONTEAGUDO ROBLEDO, José Ignacio (Eds.).

Esos papeles tan llenos de vida. Materiales para el estudio y edición de documentos personales. Gerona: G Edicions, 2009c. p. 14-15.

SIERRA BLAS, Verónica. Autobiografías en miniatura. Apuntes y reflexiones sobre la correspondencia infantil. Tempo e Argumento, Florianópolis, v. 7, n. 15, p. 42-70, mai./ago. 2015.
VILANOVA, Antonio. Los olvidados. Los exiliados españoles en la Segunda Guerra Mundial. París: Ruedo Ibérico, 1969.

YOUNES, Ebtehal. Les enfants de la débâcle: visions de guerre et traumatismes. In: Enfants de la guerre civile espagnole. Vécus et représentations de la génération née entre 1925 et 1940. París: L'Harmattan; Fondation Nationale des Sciences Politiques; Centre d'Histoire de l'Europe du Vingtième Siècle (CHEVS), 1999. p. 207-223.

ZAFRA, Enrique; CREGO, Rosalía; HEREDIA, Carmen. Los niños españoles evacuados a la URSS (1937). Madrid: Ediciones de la Torre, 1989.

Recebido em: 17.04.2017

Aprovado em: 20.07.2017

Verónica Sierra Blas é Profesora Contratada Doctora de la Facultad de Filosofía y Letras - Departamento de Historia y Filosofía, Universidad de Alcalá. Seminario Interdisciplinar de Estudios sobre Cultura Escrita (SIECE). Grupo de Investigación Lectura, Escritura, Alfabetización (LEA). e-mail: veronica.sierra@uah.es

C/ Colegios, 2 - E28801, Alcalá de Henares (Madrid) - ESPAÑA

$+0034918854428$ 